\title{
CONTROLE SOCIAL E O SERVIÇO SOCIAL NO PET-SAÚDE DA FAMÍLIA NA UBSF JOSÉ MARIA DE VASCONCELOS NETO
}

\author{
SOCIAL CONTROL AND SOCIAL-PET IN THE FAMILY HEALTH UBSF \\ JOSÉ MARIA DE VASCONCELOS NETO
}

\author{
Andréa Tenório Barros Santana ${ }^{1}$ \\ Josyanne Pereira da Silva ${ }^{2}$ \\ Thayse Heleny da Silva Agostinho ${ }^{3}$ \\ Telma Cristiane Sasso de Lima ${ }^{4}$
}

\section{RESUMO}

O artigo relata a experiência da equipe de assistentes sociais no Programa de Educação pelo Trabalho em Saúde da Família na Unidade José Maria de Vasconcelos Neto em Maceió/Alagoas durante o ciclo 2010-2012. Destacam-se as ações de controle social no Conselho Gestor Local de Saúde a partir da revisão bibliográfica, análise documental e observação participante realizada no nível de atenção básica. A síntese desse processo articula a experiência vivida ao controle social, aos marcos político-institucionais do Sistema Único de Saúde brasileiro e as ações profissionais do assistente social. Através das ações socioeducativas nos espaços coletivos de debates é possível mapear as demandas e necessidades reais da população e estimular sua participação democrática no Conselho Local de Saúde. A assessoria técnica contínua levou à mobilização em prol do exercício do controle social na saúde até os grupos operativos multiprofissionais e salas de espera. A capacidade de articulação usuárioprofissional-instituições demonstrada pela equipe de assistentes sociais contribuiu para o início da articulação em redes, seja entre níveis de atenção do Sistema Único de Saúde, ou entre as políticas e serviços sociais, contribuindo com a formação de novo perfil profissional voltado para a integralidade da atenção em saúde.

PALAVRAS-CHAVE: Política de Saúde. Sistema Único de Saúde (SUS). Controle Social. Programa Educação para o Trabalho em Saúde da Família (PET-Saúde).

\footnotetext{
${ }^{1}$ Assistente Social na UBSF José Maria de Vasconcelos Neto e do CRAS Sônia Sampaio em Maceió, preceptora PET-Saúde da Família 2010-2012 da FSSO/UFAL-Maceió /AL. Fone: 82 8841-8876. E-mail: andreatbsantana@oi.com.

${ }^{2}$ Assistente Social, monitora bolsista PET-Saúde da Família 2010-2012, Maceió/AL. E-mail: josys.social@hotmail.com.

${ }^{3}$ Assistente Social, monitora bolsista PET-Saúde da Família 2010-2012. E-mail: thayse_agostinho@hotmail.com

${ }^{4}$ Professora da Faculdade de Serviço Social UFAL/Maceió; Doutoranda em Serviço Social na UFSC/Florianópolis (2013-2017); tutora PET-Saúde da Família 2010-2012, tutora da Residência Multiprofissional em Saúde do Adulto e Idoso no HUPAA/UFAL, 2010-2011. Fone: 829985 5514. E-mail: telmasasso@gmail.com.

Serv. Soc. \& Saúde, Campinas, SP v.14, n. 2 (20), p. 245-260, jul./dez. 2015 ISSN 1676-6806
} 


\section{ABSTRACT}

The article reports the experience's social workers team on the Education Program for Work in Family Health at Health Unit José Maria de Vasconcelos Neto in Maceió/Alagoas during 20102012. We highlight the actions of social control in the Local Management Council Health from the literature review, document analysis and participant observation conducted in the primary care level. The synthesis of this process relates the experience with social control, the political and institutional frameworks of the Unified Health System Brazilian and professional actions of the social worker. Through social and educational activities in the collective debates spaces was possible to map the real demands and needs of the population and encourage their democratic participation in the Local Health Council. The continuous technical assistance led to the mobilization for the exercise of social control in health to the operating groups multidisciplinary and waiting rooms. The ability to link user-professional-institutions demonstrated by the social workers team contributed to the start of networks articulations, either between levels of care of the Unified Health System, or between the political and social services, stimulating the formation of new professional profile facing the integrality of health care.

KEYWORDs: Health Policy. Unified Health System (SUS). Social Control. Education Program for Work in Family Health (PET-Health).

\section{INTRODUÇÃO}

O surgimento das políticas sociais sempre esteve associado às reivindicações da classe trabalhadora e no reconhecimento da legitimidade social das suas necessidades, sem deixar de, ao mesmo tempo, favorecer a expansão do capitalismo, minimizando os conflitos entre as classes. Os sistemas de proteção social criados a partir daí adquiriram características e enfoques diferenciados, conforme o contexto político-econômico-social no qual foram desenvolvidos. De forma geral, instituíram e organizaram a intervenção do Estado na execução de bens e serviços coletivos implementados pelas políticas sociais.

No Brasil, esse sistema de proteção social assegurado pelo Estado conforme a chamada “Seguridade Social”, legalizada pela Constituição Federal de 1988, segundo Art.194 cuja definição refere-se a "um conjunto integrado de ações de iniciativa dos poderes públicos e da sociedade, destinados a assegurar os direitos relativos à saúde, à previdência e à assistência social” (BRASIL, 2008, p. 127).

Desde seu reconhecimento, a Seguridade Social é permeada por contradições: ao mesmo tempo em que legalmente instaura políticas públicas, algumas de caráter universal, no cotidiano dos serviços que a materializam vive-se um cenário extremamente excludente devido sua precariedade e a cultura política local que restaura paternalismos e formas de corrupção inovadoras (CORREIA, 2005).

Serv. Soc. \& Saúde, Campinas, SP v. 14, n. 2 (20), p. 245-260, jul./dez. 2015 ISSN 1676-6806 
A perspectiva Neoliberal fortalece o desmonte do aparato público de execução dos serviços sociais, subvertendo conceitos como:

[...] descentralização entendida como responsabilidade sóciocomunitária local na provisão e execução das políticas sociais; privatização regulamentação e repasse do gerenciamento dos serviços públicos para o setor privado considerado como mais eficiente; focalização que orienta a seleção dos indivíduos e situações limites encontrados no âmbito dos segmentos sociais, ou seja, dentre os pobres escolhem-se os mais pobres através de critérios rígidos de acesso e permanência nos programas de transferência de renda ou nos demais serviços sociais (CORREIA, 2005, p.149).

Aspectos estes que recaem na Política Pública de Saúde, mesmo tendo superado legalmente pós-Constituição de 1988 a concepção privatista, médico-centrada, curativa, assegurando apenas os trabalhadores formais tal como os seguros sociais. Na atualidade, a saúde brasileira vive o desafio de concretizar o acesso dos cidadãos a serviços que materializem o avanço legal e institucional do SUS conforme a Lei 8.080/1990 que reconhece a legitimidade das condições sociais para a promoção, proteção e recuperação da saúde, bem como da ação do Estado na organização do funcionamento dos serviços de saúde (BRASIL, 2012).

A conquista do SUS conecta o Brasil aos debates internacionais sobre o conceito ampliado do processo saúde/doença, no sentido de reconhecer os impactos no bem-estar individual, familiar e comunitário dos determinantes socioeconômicos e culturais, conforme recomendações da Organização Mundial da Saúde - OMS, que entende por saúde o estado de completo bem-estar físico, mental e social, e não apenas ausência de doença (OMS, 1948). Assim, o texto constitucional amplia a concepção de saúde ao informar, segundo o Artigo 196 da CF/88, que:

A saúde é direito de todos e dever do Estado, garantido mediante políticas sociais e econômicas que visem à redução do risco de doença e de outros agravos e ao acesso universal e igualitário às ações e serviços para sua promoção, proteção e recuperação (BRASIL, 2008, p. 129).

Além disso, reconhece a saúde como direito universal que deve atender sem distinção toda a população, desde as campanhas de vacinação, ações preventivas, vigilância sanitária, até as ações de alta complexidade. Para concretizar ações em prol desse avanço conceitual foram elaboradas diretrizes para o SUS de modo a efetivar a descentralização, o atendimento integral e à participação da comunidade na gestão de recursos e serviços de saúde (BRASIL, 2006). 
Desde a implantação do SUS, sua gestão deve ser descentralizada, democrática e participativa, garantindo serviços de qualidade e competentes. "O financiamento de ser transparente e repassado fundo a fundo, com contrapartidas das três esferas de governo e de acordo com a produção dos serviços da saúde e da renda per capita nacional” (CORREIA, 2005, p.166).

É importante ressaltar que a Lei 8.080/90 prevê também a articulação das políticas sociais, visualizando a intersetorialidade com os serviços que não competem à política de saúde, mas que são essências e complementares para a qualidade da saúde dos usuários.

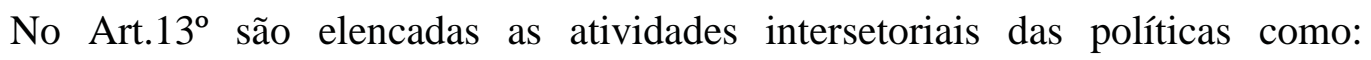
alimentação e nutrição, saneamento e meio ambiente, vigilância sanitária e farmacoepidemiologia, recursos humanos, ciência e tecnologia, e saúde do trabalhador. E para promoção e execução dessas atividades existem as Comissões Intersetoriais. Importante destacar que a complementaridade dos serviços de saúde via setor privado também é regulamentada por esta Lei, cabendo ao SUS e as agencias de saúde que o integram acompanhar, contratar e fiscalizar a relação público-privado (BRASIL, 2012).

O Art.18 da Lei 8.080/90 dispõe sobre as responsabilidades e competências municipais na implementação do SUS como ente autônomo na definição das prioridades de saúde e da alocação dos recursos. Logo, ao Município cabe suprir as necessidades da sua população de forma fidedigna à realidade social desta, é também o responsável político pela mudança do modelo de atenção à saúde no sentido de centrar ações e recursos para a promoção, prevenção e recuperação da saúde no âmbito de seu território, reconhecendo e respondendo de forma eficaz as demandas (BRASIL, 2012).

O processo de implantação do SUS, sobretudo na municipalização da Atenção Básica reatualiza a necessidade de formar um novo perfil de recursos humanos. $\mathrm{O}$ PET-Saúde surge nesse cenário como política indutora que pretende o ensino em serviço, permitindo aos graduandos da área da saúde imersão in lócu para que observem e trabalhem atentos aos debates atuais que perpassam a realização do direito à saúde (BRASIL, 2006).

O controle social é a diretriz fundamental no processo de debate em prol do SUS universal, gratuito e de responsabilidade estatal, principalmente no cenário no qual se fortalecem iniciativas de privatização, esta entendida como o repasse do gerenciamento dos recursos e serviços públicos de saúde para o setor privado. A 
inconstitucionalidade dessas iniciativas, humanização na atenção, a qualidade dos serviços, a qualificação dos recursos humanos, enfim, a mudança no modelo de atenção perpassa a formação dos profissionais de saúde, inclusive dos assistentes sociais (BRASIL, 2012; 2006).

Este artigo trata da experiência de professores, assistentes sociais-preceptores de campo e estudantes de serviço social vivida no processo de formação para o SUS através do PET-Saúde da Família. Destacam-se as ações de controle social como prioritárias porque através delas desenvolveram-se aptidões técnicas especificas e multiprofissionais, ao passo que adensaram forças ao movimento organizado da comunidade atendida pela UBSF José Maria de Vasconcelos Neto em Maceió/AL.

A metodologia seguida envolveu revisão de literatura sobre o tema; a sistematização das informações e análise documental sobre os relatos/documentação profissional e institucional que consolidam dados sobre a experiência acompanhada através das seguintes fontes documentais envolveram: diários de campo, relatórios técnicos, atas e relatos de reuniões institucionais, projetos de intervenção, planos de ação/planejamento. A observação e as ações de extensão desenvolvidas no lócus de estudo foram recursos importantes na obtenção de dados e na realização de sínteses reflexivas. As seções que compõem este artigo apresentam o percurso metodológico descrito ao passo que relata a experiência desenvolvida pela equipe de Serviço Social na atenção básica.

\section{Controle Social no SUS: marcos conceituais e legais da participação}

A partir da Lei 8.142/ 90 foi assegurada a participação da comunidade na gestão do SUS e passou a ser tratada na perspectiva de controle social, sendo assim essa lei é resultado de luta dos movimentos sociais. De acordo com Simões (2011, p. 115), “a participação popular é o meio de controle social, exercido pela sociedade civil, para a garantia dos direitos socais, superando os mecanismos tradicionais de controle técnicoburocrático”.

Essa concepção de controle social é cunhada a partir da década de 1970 quando crescem os movimentos sociais pela democracia deliberativa. No final dos anos 1980, muda a relação entre o Estado e sociedade, momento no qual segundo Correia (2003, p. 12), “o controle social passa a ser da sociedade que exerce legitimamente ações de 
fiscalização dos papeis do Estado e, consequentemente, sobre os recursos públicos de modo a colocá-los na direção dos interesses da coletividade”.

O marco deste debate, na saúde, ocorreu em 1986 na VIII Conferência Nacional de Saúde que “foi a primeira vez que a população participou das discussões [...] Suas propostas foram contempladas tanto no texto da Constituição Federal/1988 como nas leis orgânicas da saúde, $n^{\circ}$. 8.080/90 e nº 8.142/90” (BRASIL, 2012, p.1).

Assim, a participação da comunidade nas ações e serviços na área da saúde é garantida pela Constituição Federal de 1988, no inciso do III Art. 198 e regulamentada definitivamente pela Lei $n^{\circ}$ 8.142/90 através da instituição dos seguintes mecanismos de controle social:

$\S 1^{\circ}$ - A Conferência de Saúde reunir-se-á cada 4 anos com a representação dos vários segmentos sociais, para avaliar a situação de saúde e propor as diretrizes para a formulação da política de saúde nos níveis correspondentes, convocada pelo Poder Executivo ou, extraordinariamente, por este ou pelo Conselho de Saúde. $\S 2^{\circ}$ - O Conselho de Saúde, em caráter permanente e deliberativo, órgão colegiado composto por representantes do governo, prestadores de serviço, profissionais de saúde e usuários, atua na formulação de estratégias e no controle da execução da política de saúde na instância correspondente, inclusive nos aspectos econômicos e financeiros, cujas decisões serão homologadas pelo chefe do poder legalmente constituído em cada esfera do governo (BRASIL, 2012, p.1).

Segundo Correia (2003, p. 67), o papel da conferência de saúde consiste em estabelecer "uma instância colegiada de participação social que avalia a situação da saúde e propõe diretrizes para formulação de sua política nas esferas de governo correspondentes”. Apesar de não terem caráter deliberativo como os conselhos, devem ser espaços democráticos, no qual a população e os trabalhadores da saúde reivindiquem, avaliem e proponham ações na área da saúde. No Brasil já ocorreram quatro Conferências Nacionais de Saúde desde a VIII, em todas elas o SUS e a participação social foram discutidos.

Os conselhos de saúde, nas três esferas, formulam e controlam a execução das políticas de saúde, têm caráter permanente e deliberativo, exercendo fiscalização ativa na utilização dos recursos financeiros. Abrem espaço para a participação e a interferência da sociedade nos assuntos relacionados à saúde, segundo Correia (2003, p. 67), "mesmo sujeito a homologação do Executivo, abriu os caminhos para o controle social sobre os recursos públicos para a área”. 
A representação dos usuários nos conselhos é regulamentada nos $\S 4^{\circ}$ e $5^{\circ}$ do artigo $1^{\circ}$ da Lei $n^{\circ}$ 8.142/90 que prevê composição “paritária em relação ao conjunto dos demais segmentos, e terão sua organização e normas de funcionamento definidas em regimento próprio aprovado pelo respectivo Conselho” (BRASIL, 2012, p.1).

O Conselho Gestor Local da UBSF foi implantado como exigência da Política Municipal de Saúde em 08 de novembro de 2000. A primeira reunião Ordinária aconteceu em março de 2001, consolidando a participação da comunidade com os trabalhadores e gestores da política de saúde local no planejamento das ações e serviços de saúde.

Diante disso, é importante fazer um resgate histórico dos acontecimentos vividos pelo referido Conselho, no período de 2000 a 2010 que experimentou momentos de avanços e de recuos na participação de seus integrantes. As tabelas abaixo resumem o quantitativo de reuniões realizadas, as datas e o número de posses no período.

TABELA 1: Demonstrativo do número de reuniões do CGS no período de 2001-2010

\begin{tabular}{c|c}
\hline ANO & $\mathbf{N}^{\mathbf{0}}$ DE REUNIÕES \\
\hline 2001 & 04 \\
\hline 2002 & 04 \\
\hline 2003 & 05 \\
\hline 2004 & 06 \\
\hline 2005 & 10 \\
\hline 2006 & 04 \\
\hline 2007 & 07 \\
\hline 2008 & 09 \\
\hline 2009 & 06 \\
\hline 2010 & 03 \\
\hline 2011 & 07 \\
\hline
\end{tabular}

Fonte: Livro de Ata do Conselho Gestor de Saúde. 
TABELA 2: Demonstrativos das datas e locais de posse do CGS no período de 2000-2010

\begin{tabular}{c|l}
\hline \multicolumn{1}{c|}{ DATA } & \multicolumn{1}{c}{ LOCAL } \\
\hline $08 / 11 / 2000$ & Sede do V Distrito Sanitário \\
\hline $04 / 04 / 2003$ & Sede da UBSF \\
\hline $06 / 05 / 2005$ & Sede da UBSF \\
\hline $02 / 08 / 2007$ & Sede da UBSF \\
\hline $10 / 11 / 2010$ & Sede da UBSF \\
\hline
\end{tabular}

Fonte: Livro de Ata do Conselho Gestor de Saúde.

Conforme se visualiza nos dados acima houve o maior número de reuniões no ano de 2005 no qual ocorreu eleição para nova gestão do Conselho. Na chapa eleita legitimou-se a participação da assistente Social, assessora técnica, como conselheira representante o segmento trabalhador ${ }^{5}$.

A assessoria técnica ao controle social, de acordo com a Lei de Regulamentação da Profissão ( ${ }^{\circ}$ 8.662/93), consiste em uma das atribuições privativas do Assistente Social devido sua competência profissional na área. É desenvolvida através do conhecimento na realidade da participação social na comunidade na qual trabalha.

No Conselho Gestor acompanhado, o Serviço Social conseguiu em parceria aos demais conselheiros traçar prioridades de ação de acordo com as demandas apresentadas. Assumiu-se como pressuposto para a assessoria: a busca contínua pelo conhecimento com a presença em cursos e capacitações específicas que garantiram sempre maiores subsídios para que a assistente social pudesse contribuir mais com a reflexão dos conselheiros gestores.

\begin{abstract}
Assim, definimos assessoria/consultoria como aquela ação que é desenvolvida por um profissional com conhecimentos na área, que toma a realidade como objeto de estudo e detém uma intenção de alteração da realidade. O assessor não é aquele que intervém, deve, sim, propor caminhos e estratégias ao profissional ou à equipe que assessora e estes têm autonomia em acatar ou não as suas proposições. Portanto, o assessor deve ser alguém estudioso, permanentemente atualizado e com capacidade de apresentar claramente as suas proposições (MATOS, 2006, p. 05).
\end{abstract}

\footnotetext{
${ }^{5}$ O Serviço Social foi incorporado à UBSF em junho de 2004, iniciando a assessoria técnica ao no Conselho Gestor, alavancando ainda mais suas atribuições a partir de 2005 quando da participação da assistente social como conselheira gestora.

Serv. Soc. \& Saúde, Campinas, SP v. 14, n. 2 (20), p. 245-260, jul./dez. 2015 ISSN 1676-6806
} 
Os recursos que deram suporte a essa ação profissional foram: visitas institucionais às associações de moradores para conhecer as lideranças e firmar parcerias; elaboração de material didático e informativo (cartazes, panfletos e outros) sobre o Conselho Gestor e participação social conteúdo replicado, por vezes, em palestras em Sala de Espera e em Grupos de Gestantes e de Hipertensos/diabéticos de modo a sensibilizar a participação de novos sujeitos/usuários nas reuniões do Conselho.

No entanto, a partir de 2006 houve queda significativa no número de encontros entre os conselheiros devido aos problemas de infraestrutura que envolveram a UBSF: perda da sede por motivo de comprometimento da segurança pela precariedade do prédio. As atividades da UBSF ocorreram ao longo deste ano na sede de uma associação de moradores do bairro, precarizando ainda mais o atendimento e os serviços de saúde. As poucas reuniões do Conselho Gestor aconteceram precariamente em sala de associação de moradores que se encontrava abarrotada com a mobília e documentos da UBSF, por vezes os encontros foram deslocados para a Igreja Evangélica da comunidade.

Os transtornos vividos em 2006 desmotivaram as ações dos conselheiros que não viam resolutividade no atendimento das suas reivindicações públicas junto ao governo municipal. A alternativa foi acionar os representantes técnicos da Secretaria Municipal de Saúde de Maceió para participar de uma das reuniões do Conselho Gestor na sede da associação de moradores, para conferir in locu as condições de precariedade no funcionamento da UBSF. No entanto, nenhum representante compareceu nas datas agendadas e devido à falta de quórum dos conselheiros não houve deliberação de documento que formalizasse à Secretaria Municipal de Saúde as reivindicações e a necessidade de se tomar providências quanto a situação da UBSF. A mudança para nova sede ocorreu no final do ano de 2006, local no qual permanece até hoje.

Em 2007 houve mobilização para eleição de novos representantes para o Conselho. Nesse momento, todos os trabalhadores da UBSF cooperaram para a sua divulgação em busca de novos sujeitos políticos. Os Agentes Comunitários de saúde realizaram inúmeras visitas domiciliares para esse fim e houve afixação de cartazes nas associações de moradores, pontos comerciais, Órgão Públicos e Igrejas do bairro. Em agosto de 2007 ocorreu a posse da nova gestão.

No período de 2007 a 2009, as reuniões aconteceram com certa sistemática, porém devido o pouco interesse político da comunidade em se envolver com o Conselho Serv. Soc. \& Saúde, Campinas, SP v.14, n. 2 (20), p. 245-260, jul./dez. 2015 ISSN 1676-6806 
Gestor, a gestão eleita em 2007 foi reconduzida a mais um mandato, conforme orientação da equipe de Controle Social da SMS. Essa recondução gerou pouca assiduidade dos conselheiros, resultando na inatividade do mesmo entre 2009-2010.

Esse cenário insere o PETSaúde na UBSF e a prioridade de trabalho estabelecida durante o planejamento participativo local pelo grupo tutorial foram as ações de mobilização em prol do controle social devido ao reconhecimento do histórico de lutas das lideranças e da participação popular na comunidade. A próxima seção versa sobre essa experiência.

\section{O PETSaúde da Família e as ações de Controle Social na USF José Maria de Vasconcelos Neto}

O Programa de Educação pelo Trabalho para a Saúde - PET-Saúde - foi regulamentado pela Portaria Interministerial $n^{\circ}$ 421/2010, disponibilizando bolsas para tutores, preceptores (profissionais dos serviços) e estudantes de graduação na área de Saúde. O Programa tem como pressuposto a educação pelo trabalho e compõe uma das estratégias do Programa Nacional de Reorientação da Formação em Saúde, o PROSAÚDE (MS, 2012).

A prioridade consiste em efetivar a integração ensino-serviço-comunidade através da institucionalização de protocolos para a formação de um novo perfil profissional cujas parcerias envolvem Instituições de Ensino Superior, Secretarias Municipais de Saúde e Ministério da Saúde (MS, 2012). A metodologia de trabalho envolve grupos de aprendizagem tutorial em áreas estratégicas para o SUS, caracterizando-se como instrumento para a qualificação em serviço dos profissionais de saúde, bem como de iniciação ao trabalho e vivências dirigidas aos estudantes das graduações em Saúde, conforme seus objetivos específicos:

- Facilitar o processo de integração ensino-serviço-comunidade;

- Institucionalizar as atividades pedagógicas dos profissionais dos serviços de saúde;

- Valorizar estas atividades pedagógicas;

- Promover a capacitação docente dos profissionais dos serviços;

- Estimular a inserção das necessidades do serviço como fonte de produção de conhecimento e pesquisa na Universidade; 
- Incentivar o ingresso de profissionais do serviço na carreira docente (Ministério da Saúde, 2012).

Em 2010 o PET-Saúde foi inserido na UBSF para desenvolver ações multiprofissionais de fortalecimento ao Controle Social, humanização da atenção e de combate a mortalidade infantil, conforme o planejamento participativo dos grupos tutoriais que compõem o Programa. A UBSF absorveu estudantes dos cursos de graduação em Serviço Social, Enfermagem e Farmácia que metodologicamente formaram grupo multidisciplinar para trabalhar as diretrizes planejadas.

Nesse momento o Conselho Gestor Local encontrava-se desarticulado em 2010, tornando-se assim uma das ações prioritárias do grupo multiprofissional na UBSF. O objetivo inicial consistiu na mobilização da comunidade (usuários e profissionais) para a reestruturação das ações do Conselho, formando chapa para concorrer à eleição. A premissa consistia em contribuir para a consolidação de participação política atuante e comprometida com a comunidade, socializando seu papel e importância na gestão da política de saúde local.

O planejamento das ações de mobilização da comunidade para a realização da eleição envolveu as seguintes atividades:

- Balizamento teórico-conceitual dos graduandos/monitores PETSaúde envolvidos nas ações;

- Elaboração e distribuição de material educativo/informativo;

- “Salas de espera” e palestras nos grupos de Hipertensos/ Diabéticos e Gestantes informando do papel do conselheiro gestor/usuário, da data da inscrição de chapa, de eleição e posse;

- Visitas institucionais às Associações de moradores, resgatando parcerias com as lideranças da comunidade.

A eleição ocorreu em 27 de Setembro de 2010, e a posse dos conselheiros foi em novembro. As atribuições do Conselho Gestor local se desenvolveram ao longo de 2011 com a articulação entre conselheiros, monitores PET-Saúde da UBSF e de outras UBSF no município de Maceió.

A articulação entre os Conselhos Gestores locais do bairro São Jorge, São José/Canaã e São Vicente de Paula Pinheiro, além das associações de moradores dos Serv. Soc. \& Saúde, Campinas, SP v.14, n. 2 (20), p. 245-260, jul./dez. 2015 ISSN 1676-6806 
bairros circunvizinhos, resultou na reivindicação pública de melhores condições na oferta e marcação de consultas e exames especializados pelo SISREG (Sistema de Regulação). Houve a elaboração de Abaixo Assinado com coleta de assinaturas em atos públicos pela cidade que foi entregue ao Conselho Municipal de Saúde, cobrando providências necessárias à solução do problema e, posteriormente, adensou denuncia no Ministério Público Estadual, além de ser publicizado na Conferencia Nacional de Saúde de 2011.

Outra parceria importante ocorrida em 2011 foi com o Fórum Alagoano em Defesa do SUS e Contra a Privatização que fomentou o debate na UBSF e na comunidade sobre as iniciativas de privatização do SUS, alertando a todos os presentes sobre a necessidade da luta diária pela aprovação da Ação Direta de Inconstitucionalidade (ADI-1923-98) contra a Lei das Organizações Sociais (OS). Os conselheiros gestores locais participaram ainda de ações promovidas pelo Fórum: panfletagem no centro da cidade, divulgando massivamente as implicações do processo de privatização dos serviços públicos de saúde.

A relação público-privado foi tema ainda de capacitação dos conselheiros gestores locais e das lideranças da comunidade que têm assento no Conselho Municipal ou Estadual de Saúde de modo a se posicionarem politicamente nas Conferências Distrital, Municipal e Estadual de Saúde, nas quais elaboraram Moções de repúdio às ameaças de privatização do SUS.

Destaca-se a contribuição da equipe de Serviço Social PET-Saúde que estimulou a participação dos conselheiros locais nas reuniões ordinárias do Conselho Municipal de Saúde, como também no Fórum para Conselheiros com intuito de estreitar a interlocução das bases, contribuindo no debate e na deliberação de pautas em prol da melhoria na qualidade e na oferta de Serviços de Saúde no município.

A reunião ordinária do CGS de dezembro/2011 teve como pauta a avaliação anual de gestão, destacando os resultados obtidos através do resgate dos principais temas/problemas discutidos nas reuniões realizadas, a saber:

- Foram realizadas 7 reuniões, sendo 5 ordinárias e 2 extraordinárias;

- Necessidade de capacitação específica para conselheiros;

- Necessidade de capacitação em Humanização, destinada aos conselheiros e trabalhadores da UBSF para melhor qualificação dos funcionários no atendimento ao usuário. 
As metas estabelecidas para 2012 foram:

- Estimular a participação dos usuários e a assiduidade dos conselheiros nas reuniões;

- Aumentar o número de reuniões ordinárias, respeitando o mínimo de uma reunião para cada mês do ano;

- Realizar capacitação específica para conselheiros;

- Realizar capacitação em Humanização para conselheiros e funcionários;

- Continuar a assessoria realizada em 2011 pela equipe de Serviço Social do PETSaúde, através da entrega do cronograma de todas as reuniões do ano aos conselheiros, informando-os sobre as datas das reuniões e sensibilizando em sala de espera a comunidade para a participação no Conselho gestor local.

Vale ressaltar que o início de 2012 estabeleceu-se parceria com os assessores técnicos do Conselho Municipal de Saúde para realização da capacitação para conselheiros gestores. Durante a elaboração deste artigo, a capacitação aconteceu no período de 11 a 18 de abril na sede da UBSF. Destaca-se que também está agendada a capacitação sobre Humanização na Atenção em Saúde para a primeira quinzena de maio quando acontecerá a visita da equipe da Câmara Técnica em Humanização do Estado de Alagoas à Unidade, compromisso articulado pela equipe de Serviço Social no PETSaúde da Família que conjuntamente conduzirão os aspectos do tema a serem abordados na capacitação.

\section{CONCLUSÃO}

O Serviço Social teve papel fundamental devido às ações socioeducativas que garantiram a socialização de informações sob a ótica do direito em prol do fortalecimento da autonomia dos usuários e de sua participação em espaços coletivos de debates onde inscreveram suas demandas e necessidades. Exercitou-se um Conselho Gestor como um espaço democrático de controle social, no qual o Serviço Social trabalha diretamente.

A assessoria técnica prestada ao conselho gestor espraiou-se para os grupos de gestantes, hipertensos e diabéticos, além das salas de espera onde foram realizadas sensibilização e mobilização referentes ao controle social. As pautas sobre a 
privatização do SUS e as ações da equipe de Serviço Social também foram debatidas nesses espaços.

Diante da contribuição dada pelo PET-Saúde, mais especialmente pelo Serviço Social na efetivação do espaço de Controle Social via Conselho, sente-se a necessidade de assumir tal acompanhamento como um desafio diário, através de assessoria técnica contínua. Ação esta sob coordenação direta da assistente social desde sua inserção na UBSF em 2004.

A partir da experiência vivida, destaca-se a possibilidade concreta de realização da autonomia da população usuária na participação social, pois quando ouvida sabe-se que é capaz de falar sobre o que precisa, de definir prioridades, de entender os aspectos financeiros e institucionais que circundam a política de saúde. São, portanto, sujeitos no processo que dá acesso ao direito à saúde.

Para a formação acadêmica, a participação no PET-Saúde da Família foi riquíssima devido às inúmeras oportunidades de imersão na realidade cujas ações de ensino, pesquisa e extensão transcenderam as ações de controle social destacadas nesse artigo. A capacidade de articulação usuário-profissional-instituições trazida pelo Serviço Social contribuiu para o inicio da articulação em redes seja entre níveis de atenção do SUS ou entre as políticas e serviços sociais, e contribuir com o nosso conhecimento adquirido na universidade. Espera-se que o passo dado pela política indutora PRO/PET-Saúde se institucionalize na UFAL-Maceió de modo a estreitar a relação Universidade-serviços públicos-comunidade de modo a cumprir com sua função social ao envolver-se ativamente com as comunidades circunvizinhas, ampliando as ações extensionistas e consolidando o ensino interdisciplinar e crítico.

Recebido em 24.03.2015 - Reapresentado e Aprovado em 08.12.2015

\section{REFERÊNCIAS}

BRASIL. Constituição (1988). Constituição da República Federativa do Brasil: texto constitucional promulgado em 5 de outubro de 1988, com alterações adotadas pelas Emendas Constitucionais n ${ }^{0}$ 1/92 a 56/2007 e pelas Emendas Constitucionais de Revisão nº 1 a 6/94. 464 p. Brasília: Senado Federal, Subsecretaria de Edições Técnicas, 2008. 
BRASIL. Ministério da Saúde. Lei $\mathbf{n}^{\mathbf{0}}$ 8.080/90 e Lei complementar de $\mathbf{n}^{\mathbf{0}}$ 8142/90. MS - Assessoria de Comunicação Social. Brasília. Disponível em http://www.planalto.gov.br/ccivil_03/leis/L8142.htm. Acessado em 15 de abril de 2012. BRASIL. Ministério da Saúde. Política Nacional de Atenção Básica. Secretaria de Atenção à Saúde. Departamento de Atenção Básica, Secretaria de Atenção à Saúde. (Série Pactos pela Saúde 2006, v. 4). (Série A. Normas e Manuais Técnicos). 60 p. Brasília: Ministério da Saúde, 2006.

CORREIA, M. V. C. Desafios para o controle social: subsídios para capacitação de conselheiros de saúde. Rio de Janeiro: Editora Fiocruz, 2005.

CORREIA, M. V. C. Que Controle Social? Os conselhos de saúde como instrumento. $1^{\text {a }}$ reimpr. Rio de Janeiro: Fiocruz, 2003.

\section{LIVRO ATA DE REUNIÕES. CONSELHO GESTOR LOCAL DE SAÚDE DA} UBSF SÃO JORGE/JOSÉ MARIA DE VASCONCELOS NETO. 2012 MIMEO.

MATOS, M. C. Assessoria e Consultoria: reflexões para o Serviço Social. In: BRAVO, M. I. S.; MATOS, M. C. Assessoria, Consultoria e Serviço Social. Rio de Janeiro: 7 Letras; FAPERJ, 2006.

MINISTÉRIO DA SAÚDE. Programa de Educação pelo Trabalho para a SaúdePET-Saúde. Disponível www.saude.gov.br. Acessado em 14 de março de 2012. SIMÕES, C. Curso de Direito do Serviço Social. 5. Ed. São Paulo: Cortez, 2011. (Biblioteca básica de Serviço Social; V. 3).

VIII CONFERÊNCIA NACIONAL DA SAÚDE. Disponível em http://portal.saude.gov.br/portal/saude/cidadao/area.cfm?id_area=1124. Acessado em 15 de março de 2012.

WORLD HEALTH ORGANIZATION. Health promotion: a discussion document on the concept and principles of health promotion. Health Promot, n. 1, p. 73-78, 1984. 
